\title{
Bioactive glass-ceramic bone repair associated or not with autogenous bone: a study of organic bone matrix organization in a rabbit critical-sized calvarial model
}

\author{
Claudia Cristina Biguetti ${ }^{1,2}$ - Franco Cavalla ${ }^{3}$. Carla Roberta Tim ${ }^{4} \cdot$ Patrícia Pinto Saraiva $^{1} \cdot$ Wilson Orcini $^{5}$. \\ Leandro De Andrade Holgado $^{6}$. Ana Claudia Muniz Rennó ${ }^{7}$ • Mariza Akemi Matsumoto ${ }^{8}$
}

Received: 2 August 2017 / Accepted: 16 April 2018 / Published online: 26 April 2018

(C) Springer-Verlag GmbH Germany, part of Springer Nature 2018

\begin{abstract}
Objective The aim of the study was to analyze bone matrix (BMX) organization after bone grafting and repair using a new bioactive glass-ceramic (Biosilicate ${ }^{\circledR}$ ) associated or not with particulate autogenous bone graft.

Material and methods Thirty rabbits underwent surgical bilateral parietal defects and divided into groups according to the materials used: (C) control — blood clot, (BG) particulate autogenous bone, (BS) bioactive glass-ceramic, and BG + BS. After 7,14 , and 30 days post-surgery, a fragment of each specimen was fixed in $-80^{\circ} \mathrm{C}$ liquid nitrogen for zymographic evaluation, while the remaining was fixed in $10 \%$ formalin for histological birefringence analysis.

Results The results of this study demonstrated that matrix organization in experimental groups was significantly improved compared to $\mathrm{C}$ considering collagenous organization. Zymographic analysis revealed pro-MMP-2, pro-MMP-9, and active (a)-MMP-2 in all groups, showing gradual decrease of total gelatinolytic activity during the periods. At day 7, BG presented more prominent gelatinolytic activity for pro-MMP-2 and 9 and a-MMP-2, when compared to the other groups. In addition, at day 7, a 53\% activation ratio (active form/[active form + latent form]) was evident in C group, 33\% in BS group, and 31\% in BG group.

Conclusion In general, BS allowed the production of a BMX similar to BG, with organized collagen deposition and MMP-2 and MMP-9 disponibility, permitting satisfactory bone remodeling at the late period.

Clinical relevance The evaluation of new bone substitute, with favorable biological properties, opens the possibility for its use as a viable and efficient alternative to autologous bone graft.
\end{abstract}

Keywords Biomaterials $\cdot$ Bone repair $\cdot$ Picrosirius red $\cdot$ Vitroceramic $\cdot$ Zymography

Claudia Cristina Biguetti

Claudiabiguetti@Hotmail.Com

1 Research and Postgraduate Pro-Rectory, Universidade do Sagrado Coração - USC, Rua Irmã Arminda 10-50, Jardim Brasil Bauru, SP 17011-160, Brazil

2 Oral Biology Doctoral's Program, Bauru School of Dentistry, São Paulo University - FOB/USP, Alameda Octávio Pinheiro Brizola 9-75, Vila Universitária, Bauru, SP 17012-901, Brazil

3 Department of Conservative Dentistry, School of Dentistry, Universidad de Chile, Sergio Livingstone 943, Recoleta, Santiago, RM, Chile

4 Biotechnology Doctoral's Program, São Carlos Federal University UFSCAR, Rodovia Washington Luís, km 235, SP-310, São Carlos, SP 13565-905, Brazil
5 Molecular Biology Laboratory, Research and Postgraduate Pro-Rectory, Universidade do Sagrado Coração - USC, Rua Irmã Arminda 10-50, Jardim 17011-160, Brazil

6 Discipline of Oral and Maxillofacial Surgery, Department of Health Sciences, Universidade Sagrado Coração - USC, Rua Irmã Arminda 10-50, Jardim Brasil Bauru, SP 17011-160, Brazil

7 Department of Bioscience, Federal University of São Paulo, Campus Baixada Santista - UNIFESP, Avenida Ana Costa, 95 - Vila Matias, Santos, SP 11060-001, Brazil

Discipline of Histology and Embriology, Department of Basic Sciences, São Paulo State University - FOA/UNESP, Rua Paul Harris 1100, Casa 03, Jardim Nova Iorque Araçatuba, SP 18016-110, Brazil 


\section{Introduction}

Bone defect repair and regeneration are supposed to be one of the more challenging issues in the field of oral and maxillofacial surgery, especially to recover defects resulting from trauma and pathology sequel $[1,2]$. Indeed, the necessity of the development of synthetic bone substitutes for recovering oral function has increasingly encouraged studies on tissue engineering $[3,4]$. In this way, a new third generation of fully crystalline particulate glass-ceramic (Biosilicate ${ }^{\circledR}$, Vitrovita, São Carlos, Brazil; WO 2004/074199) [5-7] has demonstrated interesting results in previous in vitro and in vivo studies [8-12].

Along with the satisfactory biological behavior of Biosilicate $^{\circledR}$, it also presents mechanical properties that surpass the available bioglasses [6], adding to this material a characteristic that turns it into a promising bone substitute when load bearing condition is required. Although it is known that ceramics and glass-ceramics present better biomechanical properties when compared to the bioactive glasses, the improved mechanical capacity of Biosilicate ${ }^{\circledR}$ has been attributed to the fact that hydroxyapatite is formed only through superficial chemical reactions between the biomaterial and living tissues, in a way that no phase based on calcium phosphate is crystalized during the glass-ceramic production. In addition, it is highly bioactive $\left(\mathrm{I}_{\mathrm{B}}>8\right)$ and its elasticity modulus is comparable to bone tissue [12]. Biomechanical investigation using Biosilicate ${ }^{\circledR}$ to fill non-critical tibial defects of rats confirms this property, since it improved maximum load of failure and stiffness when compared with the control defects, exhibiting similar bone mechanical behavior than the intact tibias [10]. These results permitted researchers to attempt other applications of this glass-ceramic biomaterial, such as for alveolar ridge reconstruction for further rehabilitation with dental implants. Roriz et al [11] comparing Biosilicate ${ }^{\circledR}$ with the bioglass Biogran ${ }^{\circledR}$ in extracted dental sockets of dogs observed that both materials preserved alveolar bone ridge height and allowed titanium implant osseointegration that could be confirmed by the percentages obtained from bone morphometry after 8 weeks.

Along with the improved biomechanical properties, its bioactivity and osteogenesis capacity has already been revealed in previous in vitro and in vivo studies $[12,13]$. Recent study about this effect on calvarial defects of rabbits presented significant capacity of the biomaterial to stimulate bone formation, revealing similar results when compared with particulate autogenous bone grafts with intense immunolabeling for Cbfa-1/Runx-2 and VEGF [14].

Despite these encouraging results, the characteristics of the bone matrix in the presence of Biosilicate ${ }^{\circledR}$ have not been studied so far. It is known that not only bone-forming capacity is enough to qualify a biomaterial, but also its capacity of inducing a good quality bone, especially when the site of its application demands strength. Considering the highly hierarchical structure of bone, microarchitecture of the newly formed and remodeling bone depends on the structural organization of organic bone matrix, mainly formed by collagen component $[15,16]$. The highest modulus and monotonic bone strength has been achieved when collagen fibers are longitudinally disposed in tissue, which can be confirmed under polarized light by the birefringence measurement [17-19].

Another component of bone matrix that directly influences the biomechanical properties of bone is the matrix metalloproteinases (MMPs), which compound a family of zincdependent proteolytic enzymes $[18,19]$ that process both helical and denature type I collagen, especially MMP-2 and 9 [20]. Although presenting similar functions, MMP-2 is primarily expressed by the osteoblasts, limited to the initial phase of bone formation; on the other hand, MMP-9 has been considered a marker for osteoclastic activity [21]. Studying $M m p 2^{-/-}$and $M m p 9^{-/-}$mice, Nyman et al. [20] observed that the loss of both MMPs severely affected some architectural characteristics, revealing a weaker bone related to the lack of MMP-2 leading to a decreased mineralization tissue, and decreased bone toughness in the absence of MMP-9, since it may influence bone extracellular matrix protein organization. Additionally, MMPs also play an important role in cell signaling [22], modulating local availability of growth factors such as VEGF $[23,24]$ and significantly contributing with angiogenesis in a number of tissues [22, 25, 26].

The aim of the present study was to verify the quality of organic bone matrix formed in calvaria bone defects of rabbits treated with Biosilicate ${ }^{\circledR}$ associated or not with particulate autogenous bone graft, analyzing pro and active forms of MMP-2 and 9 levels by zymography and collagen organization using birefringence method.

\section{Materials and methods}

The Ethical Committee for Animal Research of Sagrado Coração University approved all experimental protocols used in the present study (protocol no. 110/09), and the Brazilian College of Animal Experimentation (COBEA) guidelines for the care and use of laboratory animals have been observed.

\section{Study design}

Thirty male New Zealand rabbits, age ranging from 4 to 6 months and average weight of $3.5 \mathrm{Kg}$, underwent surgical bone defect procedures, one in each parietal bones, filled with different materials resulting in four groups, as follows: blood clot (control group-C), particulate autogenous bone graft from calvarial bone (BG), bioactive glass-ceramic (Biosilicate ${ }^{\circledR}$, São Carlos, Brazil) (BS), and bioactive glassceramic associate to the particulate autogenous bone graft (BS $+\mathrm{BG})$. The animals were euthanized with anesthetic overdose 
after three experimental periods: 7, 14, and 30 days, for specimens' removal. Five specimens contained were analyzed in each group and period.

\section{Surgical procedure}

At the beginning of the experimental design, all animals underwent surgical procedures for the performance of two bone defects, one in each parietal bone to be immediately filled with different materials. For general anesthesia, intramuscular administration of $1 \%$ ketamine and $2 \%$ xylazine in the recommended dose was used. After trichotomy of the animal's head and antisepsis with $1 \%$ polyvinylpyrrolidone of the area, local anesthesia was also performed with $2 \%$ mepivacaine with adrenaline $(1: 100.000)$ in order to minimize bleeding in the surgical site. After a 4-cm incision along with the sagittal suture and dermoperiosteum reflection was performed, the defects were made using a 10-mm internal diameter trephine bur, under copious irrigation with $0.9 \%$ saline solution in both parietal bones. Total removal of the calvaria diploe was performed, but the dura-mater membrane was left intact. Each animal received two different treatments. In 15 rabbits, the right-side defects were filled with blood clot and the left-side defects were filled with the bioactive glassceramic (granules of 180-210 $\mu \mathrm{m}$ ), until the total filling of the defects. In the same way, in the other 15 animals, the rightside defects were filled with fresh particulate bone grafts, prepared with the bone retrieved during the confectioning of the defects, and in the left side, the defects were filled with a 1:1 mixture of the particulate bone graft and the glass-ceramic, compounding the four groups mentioned above. The incisions were sutured with 4-0 nylon. All the animals received $0.2 \mathrm{ml} /$ $\mathrm{Kg}$ of $2.5 \%$ enrofloxacin antibiotic for 3 days, and intramuscular injection of $5 \mathrm{mg} / \mathrm{Kg}$ of tramadol immediately after the surgical procedure.

At the end of the experimental periods, five specimens for each group were removed, and a small fragment of the defect area was immediately fixed in $-80{ }^{\circ} \mathrm{C}$ liquid nitrogen for zymography analysis and the remaining fragment was fixed in buffered 10\% formalin (Merck, Darmstadt, Germany) for $48 \mathrm{~h}$ and washed in tap water for $24 \mathrm{~h}$ before being immersed in $4 \%$ ethylenediaminetetraacetic acid (EDTA) for demineralization. Transversal semi-serial histologic slices from the wider diameter of the defect were obtained, so the central area of the defect could be observed.

\section{Picrosirius red polarization method}

Histological slices were stained with Picrosirius red, which revealed the natural birefringence of collagen fiber bundles making possible the analysis of their organization and amount, considering that the greater birefringence intensity of the collagenous matrix, the better its organization. Four central fields of the defects were analyzed under polarized light microscope with $\times 10$ magnification (Fig. 1) Specifically, when Picrosirius red stained tissue is under polarized light (Fig. 1b), only collagen fibers appear in the birefringence field, while other tissue components stay in the black background and are excluded of this analysis. According to organization of collagen fiber orientation, spectrum color of birefringence can vary from greenish (thinner fibers) to red (thicker fibers), thus reflecting fiber thickness and packing [27] (Fig. 1b). To quantify only greenish and red fibers corresponding to the newly formed collagenous matrix, bone graft particles (BG and BG + BS groups) were removed in Adobe Photoshop CS6 Software to delimit the region of interest (Fig. 1b, c). Subsequently, the processed images were evaluated in the ImageJ (version 1.36) software, to define corresponding area $\left(\mathrm{pixel}^{2}\right)$ of specific greenish and red fibers, as well as total birefringent fibers (a sum of greenish and red fibers) [28-30]. Briefly, after binarization of the target fiber (i.e., thick collagen fibers, with red color birefringence), the software converted all area containing the red color in white and this area (pix$\mathrm{el}^{2}$ ) was measured, while the area in black was automatically excluded, as demonstrated in Fig. 1d.

\section{Zymographic analysis}

Densitometry analysis of gelatine zymography was used for the detection of active (a) and latent forms (pro) of MMP. A sample pool of each experimental group containing $50 \mu \mathrm{g}$ of proteins was loaded in a $12 \%$ polyacrylamide gel containing $20 \% \mathrm{w} / v$ sodium dodecyl sulfate (SDS) and $1 \%$ gelatine. Electrophoresis was performed in reducing non-denaturing conditions at $110 \mathrm{~V}$ for $1 \mathrm{~h}$. Later, the gels were washed three times with $2 \%$ Triton X-100 in order to remove SDS and then incubated in Tris- $\mathrm{HCl} \mathrm{mM} \mathrm{pH} 7.4$ and $10 \mathrm{mM} \mathrm{CaCl}_{2}$ during $18 \mathrm{~h}$ at $37^{\circ} \mathrm{C}$. The gels were then stained for $1 \mathrm{~h}$ at room temperature with Coomassie brilliant blue $0.125 \mathrm{w} / \mathrm{v}$ solution R-250 (Sigma-Aldrich) and subsequently destained in ethanol/acetic acid (2.5:1) solution until the clear bands against a blue background could be clearly visualized.

Images obtained in 300dpis with AlphaImager ECMultilmage Light Cabinet (Alpha Innotech Corporation, San Leandro, CA, USA) containing clear bands were analyzed using ImageJ software for semi-quantitative determination of gelatinolytic activity, from the calculation of the total gelatinolytic activity and activation ratio of MMP-2 (aMMP-2/pro-MMP-2+a-MMP-2), according to previous studies $[31,32]$.

\section{Statistical analysis}

Picrosirius red data were assessed using non-parametric Kruskal-Wallis test followed by Dunn's post-test from all 
Fig. 1 Birefringence analysis of collagen matrix upon polarized microscopy exemplified by BS + $\mathrm{BG}$ group at day 14. Image captured under conventional light microscopy (a) to identify new bone formation (asterisk) featuring red birefringence on polarized light (b). Bone graft is identified by greenish fibers (a), while the glass ceramic (bs) remains in a dark background field (b). After image processing to exclude bone graft areas (c), the image was binarized (d) to quantify greenish (black) and red fibers (white) (Picrosirius red staining, original magnification $\times$ 10)
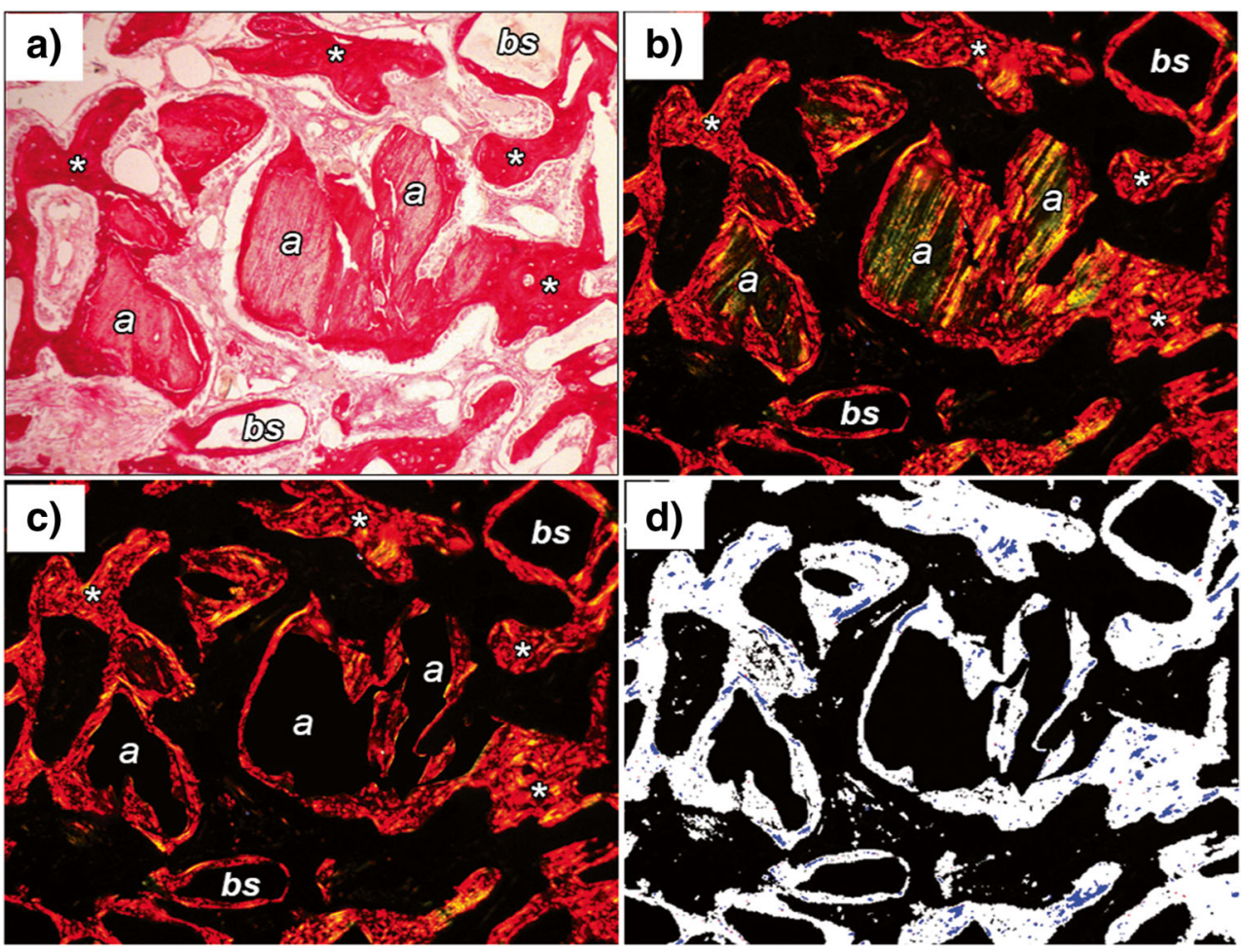

periods analyzed. Statistical comparison between only two groups at the same period was performed by Mann-Whitney test. The significance level was always set at $p<0.05$, and all statistical tests were performed using the GraphPad Prism 5.0 software (GraphPad Software Inc., San Diego, CA, USA).

\section{Results}

\section{Picrosirius red polarization analysis}

Morphogical analysis of Picrosirius-hematoxylin revealed that $\mathrm{C}$ group presented predominance of fibrous connective tissue during repair periods, while experimental groups $(\mathrm{BG}, \mathrm{BS}$, and $\mathrm{BS}+\mathrm{BG}$ ) demonstrated evident new bone formation around the grafted biomaterials from day 14 (Fig. 2). Under polarized light, all groups demonstrated formation of thick collagen fibers (red) predominantly (Fig. 3).

Quantitatively, all experimental groups (BG, BS, and BS + $\mathrm{BG}$ ) presented newly formed BMX in birefringence level statistically higher than $\mathrm{C}$ group from 7 to 30 days. However, collagenous BMX organization did not present statistically significant differences in birefringence level among the experimental groups along all periods (Fig. 4).

\section{Zymographic evaluation of gelatinolytic activity}

Zymographic analysis detected pro-MMP-2 and pro-MMP-9 and a-MMP-2, identified according to their characteristic molecular weights $(\mathrm{kDa})$, being $92 \mathrm{kDa}$ for pro-MMP-9, $72 \mathrm{kDa}$ for pro-MMP-2, and $67 \mathrm{kDa}$ for a-MMP-2, as shown in Fig. 5. In general, pro-MMP-2 was the most evident gelatinolytic band. Total gelatinolytic activity of all groups showed a gradual decrease during the periods. At day $7, \mathrm{BG}$ presented more prominent gelatinolytic activity for pro-MMP2 and 9 and a-MMP-2, when compared to the other groups. In addition, at day 7 , a 53\% activation ratio (active form/[active form + latent form]) was evident in C group, $33 \%$ in BS group, and $31 \%$ in BG group.

\section{Discussion}

The use of synthetic bone substitutes to replace or supplement the autogenous bone graft is highly recommended when the reconstruction of bone defects is aimed [4], especially before the osseointegrated implant placement in atrophic areas. In this context, synthetic biomaterials can be used to avoid or minimize the quantity of autogenous bone retrieved from patient, as well as to reduce the resorption rate of bone grafts when synthetic and autogenous bone is combined [33]. The present study aimed to analyze a novel fully crystallized vitroceramic (associated or not with autogenous bone graft) during BMX formation, taking in advantage its high level of bioactivity [10-14], adequate mechanical properties [6,7], and also antimicrobial activity [34].

Importantly, most of the studies about bone substitutes focus on their capacity of bone formation and mineralization. 


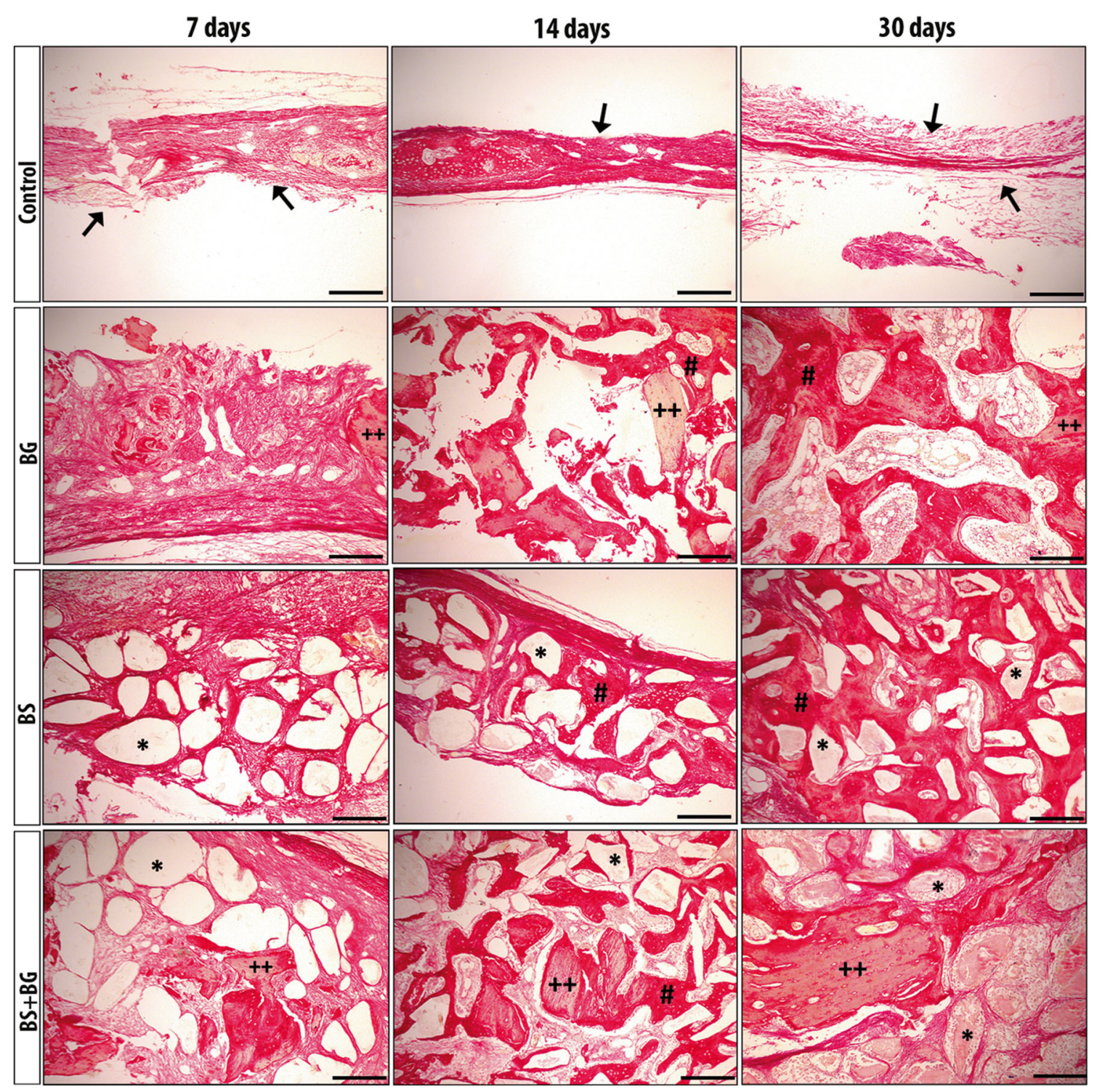

Fig. 2 Morphological analysis of Picrosirius-hematoxylin under conventional light microscopy. C group presents predominance of fibrous connective tissue (arrows) in the central region of the defect during all periods. Experimental groups $(\mathrm{BG}, \mathrm{BS}, \mathrm{BS}+\mathrm{BG})$ demonstrated evident new bone formation (number sign) around the biomaterial particles (asterisk), and bone grafts (double plus sign), specially from day 14 (Picrosirius red staining, original magnification $\times$ 10. Scale bar $=50 \mu \mathrm{m})$
However, bone tissue quality directly depends on the organization of organic matrix components, especially collagen type I, which acts as a scaffold for matrix mineralization [15]. At the beginning of bone repair, newly differentiated osteoblasts secrete bone organic component with a high content of type I collagen $(90 \%)$ that acts as a scaffold for inorganic ion deposition [35]. Therefore, quantity and spatial organization of the collagen fibers from BMX directly influence bone trabecula microarchitecture [15]. Interestingly, collagen fibers are birefringent, and when polarized light passes through its long axis, polarized waves orthogonally disposed travels in different velocities, causing a delay that must be proportional to the quantity and thickness of the aligned filaments $[27,29,36]$. Throughout bone repair, greenish birefringence color indicates thin fibers while red colors in the birefringence analysis indicate thick collagen fibers [37]. In this study, all analyzed groups in the present study demonstrated thick and thin fiber formation, with differences in the amount of collagen content between control and all experimental groups (BG, BS, BS + BG). Indeed, all grafted biomaterials demonstrated improvement in defect repair compared to the $\mathrm{C}$ group. Uniform increase of all fibers (greenish, red, and total) was observed in the BS, as well as in BG group. The significant small amount of all birefringent fibers in $\mathrm{C}$ group suggests a delay in BMX deposition, since it depended solely of the blood clot. In fact, the birefringent collagenous matrix observed in the $\mathrm{C}$ group from Picrosirius-polarized corresponded to fibrous connective tissue revealed by Picrosirius-hematoxylin under conventional light microscopy analysis in all periods, even at day 30 . 


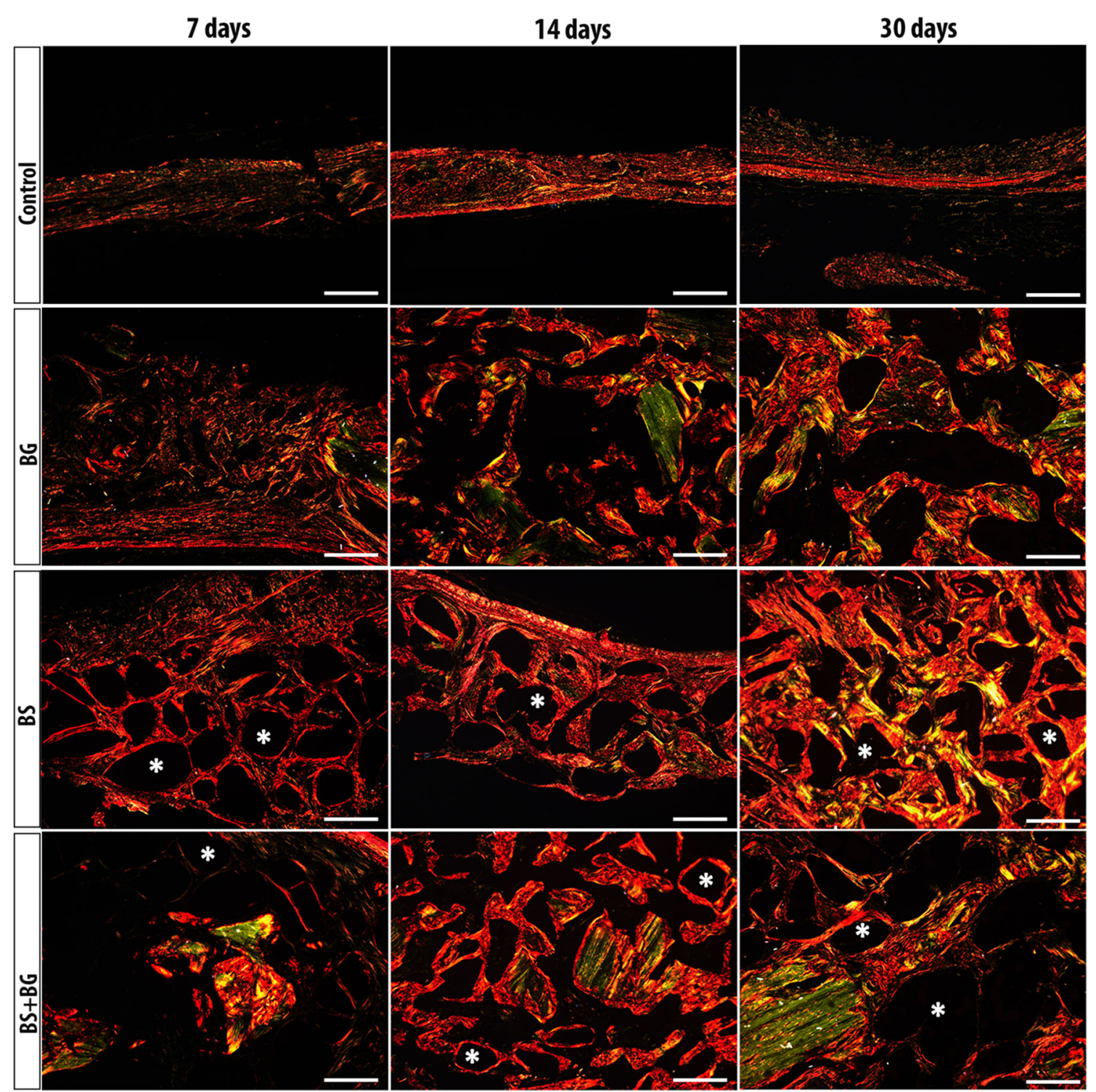

Fig. 3 Morphological analysis of Picrosirius-polarized slices. C group presented greenish and red collagen fibers in the central region of the defects during all periods. Experimental groups (BG, BS, BS + BG) demonstrated evident organization of bone collagenous matrix by the

In the presence of bone graft $(\mathrm{BG})$, greenish and red fiber birefringence increased indicating better organization of collagen I bundles, probably due to the stimulation of autogenous graft. Although bone birefringent collagenous matrix was detected in the BG group since day 14 until day 30, the trabecular configuration of the bundles could not be clearly seen. On the other hand, parallel fibers were observed in BS group since day 7 and maintained until day 30 , where bone trabeculae in a lamellar arrangement were noted. The association of BG and $\mathrm{BS}(\mathrm{BS}+\mathrm{BG})$ presented a decrease in greenish birefringence at day 30 and an increase of the red one, suggesting that this condition induces a higher organization of BMX deposition from the early stages of bone repair. In this context, a previous study using a sinus lift augmentation model in rabbits compared red fibers around the grafted biomaterial (asterisk), especially at day 14 . Autogenous bone (BG) presented greenish birefringence, while BS remained on dark background (Picrosirius red staining, original magnification $\times 10$. Scale bar $=50 \mu \mathrm{m})$

the healing process using $\mathrm{BS}, \mathrm{BS}+\mathrm{BG}$, bovine hydroxyapatite or bovine hydroxyapatite+BG. Interestingly, when BS was used isolated as a graft material, the BMX organization was delayed in comparison to the other groups, followed by an intense foreign body reaction and interfering in new bone formation and maturation [30]. Despite particularities of the different models (calvarial and maxillary sinus), these contrasting results indicate the necessity of testing new biomaterials in distinct anatomical sites, reproducing comparable methods $[14,30]$.

The gradual decline of gelatinolytic activity with time in all groups could reflect the natural process of bone graft integration and tissue maturation during the healing phase. Comparison among the groups showed higher gelatinolytic activity for proMMP-2, pro-MMP-9, and a-MMP-2 in BG group, which can 
A)

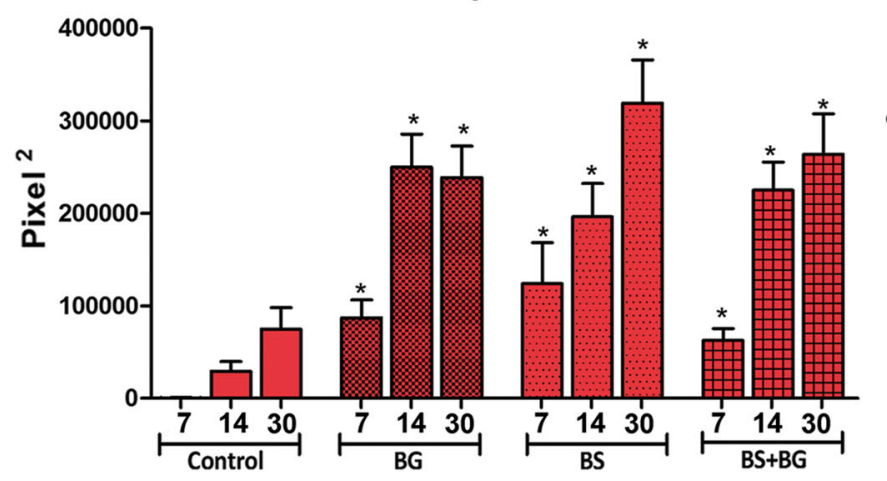

C)

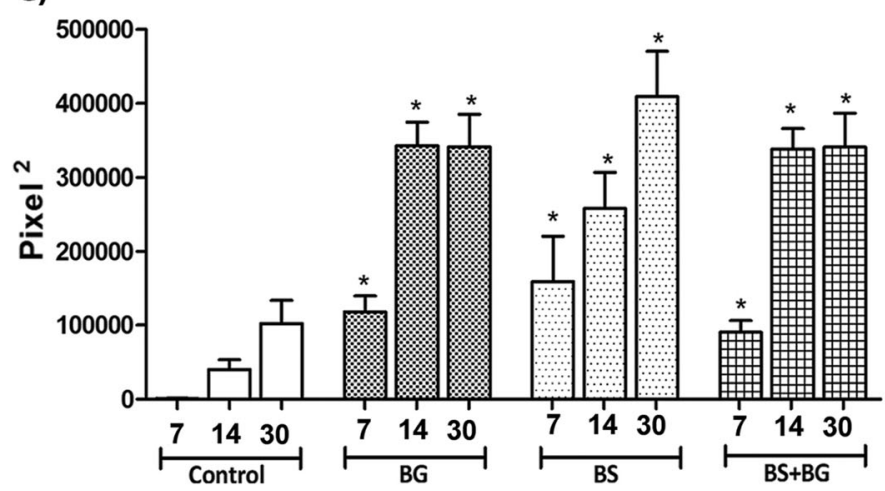

Fig. 4 Quantification of collagen fiber bundles by Picrosiriuspolarization method along graft integration. Intensity of birefringence measured from red collagen fibers (a), greenish collagen fibers (b), and

be related with the properties of the biomaterial, since autogenous grafts are known to activate MMP expression in tissue [38], as well as to bring a number of biological molecules, including MMPs, associated to the BMX [4, 22]. However, this higher activity did not interfere in qualitative/quantitative differences in newly formed collagenous from BMX organization when compared to BS group or BS + BG group, as revealed by polarized images. Taking these results into consideration, morphological analysis of polarized fibers in BS showed satisfactory integration between the glass-ceramic particles to the newly formed bone. Although the biomaterial is different from autogenous bone in terms of its intrinsic constituents, it allowed for a similar biological activity of MMP-2, since the percentage of MMP-2 activation in BS was of 33\% against 31\% in BG at day 7. Interestingly, when both biomaterials were associated, the activation of MMP-2 was completely abrogated. Since MMP-2
B)

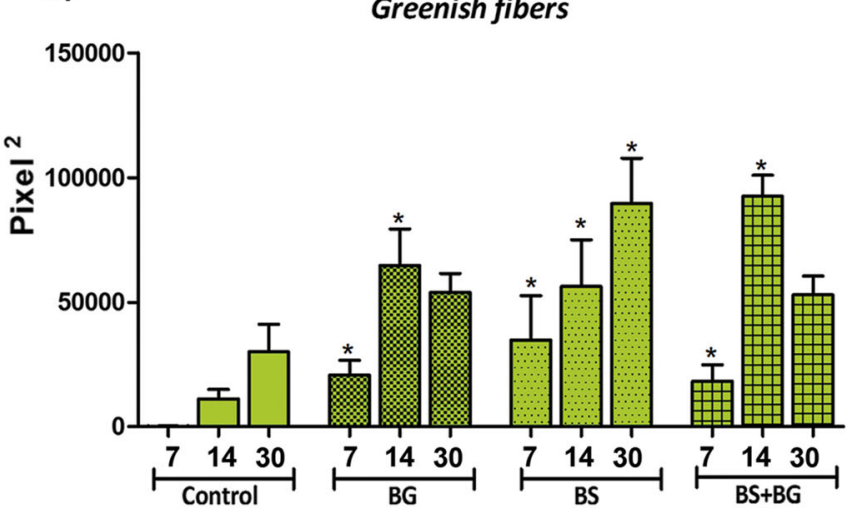

Legend:

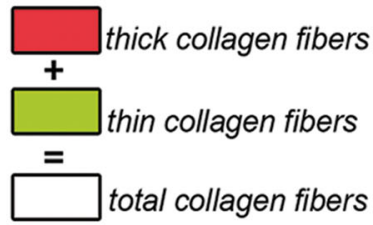

total area of collagen fibers (c). Results are presented as mean and SD of pixels $^{2}$. ${ }^{*} p<0.05$ in comparison to C group

and MMP-9 are also related with neoangiogenesis $[22,24]$ and MMP-2 is mainly expressed by osteoblasts at the beginning of bone formation [21], its initial activation detected in BS and BG groups could contribute with the initial local revascularization. Indeed, MMP-2 is an important modulator of local VEGF availability $[22,32]$. A previous study from our group showed intense VEGF immunolabeling in rabbits' calvaria defects filled with BS, similar to particulate autogenous bone grafts [14].

Although MMPs are directly related to the architectural characteristics of bone tissue [20], from our current results, it is not possible to infer that improved biomechanical properties were achieved in BS group, or in BS+BG group, since bone mineral density was not assessed. Finally, the lowest levels of MMP-9 at day 30 in all groups are indicative that bone remodeling process was controlled, since its levels and activity are related to bone resorption and bone graft remodeling [38].
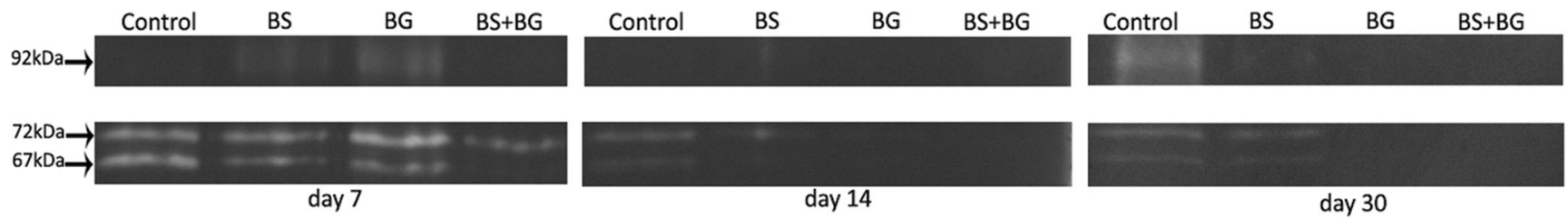

Fig. 5 Gels of densitometric analysis of gelatine zymography containing clear bands of $92 \mathrm{kDa}$ (MMP-9 latent form), $72 \mathrm{kDa}$ (MMP-2 latent form), and $67 \mathrm{kDa}$ (active form of MMP-2), from a pool of samples from each group and period 


\section{Conclusions}

Biosilicate ${ }^{\circledR}$ allowed the production of a BMX similar to BG, with organized collagen deposition and MMP-2 and MMP-9 disponibility, permitting satisfactory bone remodeling at the late period. Biosilicate ${ }^{\circledR}$ demonstrated a similar capacity to autogenous bone graft in inducing BMX deposition, organization, and remodeling during bone defect healing and repair. However, further studies are necessary focusing on different anatomical sites and animal models in order to open the possibility for its use as a viable and efficient alternative to autologous bone graft.

Acknowledgements The authors are grateful to Maira Cristina Rondina Couto for histology assistance.

Funding This work was supported by São Paulo Research Foundation (FAPESP/SP), grant numbers 2008/11485-8; 2009/17294-1.

\section{Compliance with ethical standards}

Conflict of interest The authors declare that they have no conflict of interest.

Ethical approval All procedures performed in studies involving animals were in accordance with the ethical standards of the Ethical Committee for Animal Research of Sagrado Coração University (protocol \# 110/09), and the Brazilian College of Animal Experimentation (COBEA) guidelines for the care and use of laboratory animals.

Informed consent For this type of study, formal consent is not required.

\section{References}

1. Horch RE, Kneser U, Polykandriotis E, Schmidt VJ, Sun J, Arkudas A (2012) Tissue engineering and regenerative medicine-where do we stand? J Cell Mol Med 16:1157-1165. https://doi.org/10.1111/j.1582-4934.2012.01564.x

2. Eweida AM, Nabawi AS, Abouarab M, Kayed M, Habashi E, Etaby A, Khalil MR, Shawky MS, Kneser U, Horch RE, Nagy N, Marei MK (2014) Enhancing mandibular bone regeneration and perfusion via axial vascularization of scaffolds. Clin Oral Invest 18:1671-1678. https://doi.org/10.1007/s00784-013-1143-8

3. Hench LL, Polak JM (2002) Third-generation biomedical materials. Science 295:1014-1017

4. Draenert FG, Huetzen D, Neff A, Mueller WEG (2014) Vertical bone augmentation procedures: basics and techniques in dental implantology. J Biomed Mater Res A 102(5):1605-1613. https:// doi.org/10.1002/jbm.a.34812

5. Peitl O, Zanotto ED, La Torre GP. Hench LL (1997) Patent WO/ 1997/041079

6. Zanotto ED, Ravagnani C, Peitl OF, Panzeri H, Guimarães LEH (2004) Fundação Universidade Federal de São Carlos, Universidade de São Paulo. Process and compositions for preparing particulate, bioactive or resorbable biosilicates for use in the treatment of oral ailments. Int. C. C03C10/00, WO2004/074199

7. Peitl O, Zanotto ED, Serbena FC, Hench LL (2012) Acta Biomater 8(1):321-332. Compositional and microstructural design of highly bioactive $\mathrm{P} 2 \mathrm{O} 5-\mathrm{Na} 2 \mathrm{O}-\mathrm{CaO}-\mathrm{SiO} 2$ glass-ceramics
8. Clupper DC, Gough JE, Hall MM, Clare AG, LaCourse WC, Hench LL (2003) In vitro bioactivity of S520 glass fibers and initial assessment of osteoblast attachment. J Biomed Mater Res A 67((1): 285-294. https://doi.org/10.1002/jbm.a.10040

9. Tsigkou O, Jones JR, Polak JM, Stevens MM (2009) Differentiation of fetal osteoblasts and formation of mineralized bone nodules by $45 \mathrm{~S} 5$ Bioglass conditioned medium in the absence of osteogenic supplements. Biomaterials 30(21):3542-3550. https://doi.org/10.1016/j.biomaterials.2009.03.019

10. Granito RN, Rennó AC, Ravagnani C, Bossini PS, Mochiuti D, Jorgetti V, Driusso P, Peitl O, Zanotto ED, Parizotto NA, Oishi J (2011) In vivo biological performance of a novel highly bioactive glass-ceramic (Biosilicate ${ }^{\circledR}$ ): a biomechanical and histomorphometric study in rat tibial defects. J Biomed Mater Res B Appl Biomater 97((1):139-147. https://doi.org/10.1002/jbm.b. 31795

11. Roriz VM, Rosa AL, Peitl O, Zanotto ED, Panzeri H, de Oliveira PT (2010) Efficacy of a bioactive glass-ceramic (Biosilicate) in the maintenance of alveolar ridges and in osseointegration of titanium implants. Clin Oral Implants Res 21(2):148-155. https://doi.org/10. 1111/j.1600-0501.2009.01812.x

12. Moura J, Teixeira LN, Ravagnani C, Peitl O, Zanotto ED, Beloti MM, Panzeri H, Rosa AL, de Oliveira PT (2007) In vitro osteogenesis on a highly bioactive glass-ceramic (Biosilicate). J Biomed Mater Res A 82((3):545-557. https://doi.org/10.1002/jbm.a.31165

13. van Houdt CI, Tim CR, Crovace MC, Zanotto ED, Peitl O, Ulrich DJ, Jansen JA, Parizotto NA, Renno AC, van den Beucken JJ (2015) Bone regeneration and gene expression in bone defects under healthy and osteoporotic bone conditions using two commercially available bone graft substitutes Biomed Mater. 8;10(3): 035003. doi: https://doi.org/10.1088/1748-6041/10/3/035003

14. Matsumoto MA, Caviquioli G, Biguetti CC, Holgado Lde A, Saraiva PP, Renno AC et al (2012) A novel bioactive vitroceramic presents similar biological responses as autogenous bone grafts. J Mater Sci Mater Med 23(6):1447-1456. https://doi.org/10.1007/ s10856-012-4612-8

15. Seeman E, Delmas P (2006) Bone quality - the material and structural basis of bone strength and fragility. N Engl J Med 354:2250 2261. https://doi.org/10.1056/NEJMra053077

16. Siegmund T, Allen MR, Burr DB (2008) Failure of mineralized collagen fibrils: modeling the role of collagen cross-linking. J Biomech 41(7):1427-1435. https://doi.org/10.1016/j.jbiomech. 2008.02.017

17. Martin RB, Lau ST, Mathews PV, Gibson VA, Stover SM (1996) Collagen fiber organization is related to mechanical properties and remodeling in equine bone. A comparison of two methods. J Biomech 29(12):1515-1521

18. Ramasamy JG, Akkus O (2007) Local variations in the micromechanical properties of mouse femur: the involvement of collagen fiber orientation and mineralization. J Biomech 40(4): 910-918. https://doi.org/10.1016/j.jbiomech.2006.03.002

19. Krane SM, Inada M (2008) Matrix metalloproteinases and bone. Bone 43(1):7-18. https://doi.org/10.1016/j.bone.2008.03.020

20. Nyman JS, Lynch CC, Perrien DS, Thiolloy S, O'Quinn EC, Patil CA, Bi X, Pharr GM, Mahadevan-Jansen A, Mundy GR (2011) Differential effects between the loss of MMP-2 and MMP-9 on structural and tissue-level properties of bone. J Bone Miner Res 26(6):1252-1260. https://doi.org/10.1002/jbmr.326

21. Bassil J, Senni K, Changotade S, Baroukh B, Kassis C, Naaman N, Godeau G (2011) Expression of MMP-2, 9 and 13 in newly formed bone after sinus augmentation using inorganic bovine bone in human. J Periodontal Res 46(6):756-762. https://doi.org/10.1111/j. 1600-0765.2011.01400.x

22. Rodriguez D, Morrison CJ, Overall CM (2010) Matrix metalloproteinases: what do they not do? New substrates and biological roles 
identified by murine models and proteomics. Biochim Biophys Acta 1803(1):39-54. https://doi.org/10.1016/j.bbamcr.2009.09.015

23. Zhou Z, Apte SS, Soininen R, Cao R, Baaklini GY, Rauser RW, Wang J, Cao Y, Tryggvason K (2000) Impaired endochondral ossification and angiogenesis in mice deficient in membrane-type matrix metalloproteinase I. Proc Natl Acad Sci U S A 97(8):40524057. https://doi.org/10.1073/pnas.060037197

24. Colnot C, Thompson Z, Miclau T, Werb Z, Helms JA (2003) Altered fracture repair in the absence of MMP-9. Development 130(17):4123-4133. https://doi.org/10.1242/dev.00559

25. Erler JT, Bennewith KL, Cox TR, Lang G, Bird D, Koong A et al (2009) Hypoxia-induced lysyl oxidase is a critical mediator of bone marrow cell recruitment to form the premetastatic niche. Cancer Cell 6;15(1):35-44. https://doi.org/10.1016/j.ccr.2008.11.012

26. Badiga AV, Chetty C, Kesanakurti D, Are D, Gujrati M, Klopfenstein JD, Dinh DH, Rao JS (2011) MMP-2 siRNA inhibits radiation-enhanced invasiveness in glioma cells. PLoS One 6(6): e20614. https://doi.org/10.1371/journal.pone.0020614

27. Lattouf R, Younes R, Lutomski D, Naaman N, Godeau G, Senni K, Changotade $S$ (2014) Picrosirius red staining: a useful tool to appraise collagen networks in normal and pathological tissues. $\mathrm{J}$ Histochem Cytochem 62(10):751-758. https://doi.org/10.1369/ 0022155414545787

28. Garavello-Freitas I, Baranauskas V, Joazeiro PP, Padovani CR, Dal Pai-Silva M, da Cruz-Hofling MA (2003) Low-power laser irradiation improves histomorphometrical parameters and bone matrix organization during tibia wound healing in rats. J Photochem Photobiol B 70(2):81-89. https://doi.org/10.1016/S1011-1344(03) 00058-7

29. Bossini PS, Renno AC, Ribeiro DA, Fangel R, Peitl O, Zanotto ED et al (2010) Biosilicate(R) and low-level laser therapy improve bone repair in osteoporotic rats. J Tissue Eng Regen Med 5(3):229-237. https://doi.org/10.1002/term.309

30. Vivan RR, Mecca CE, Biguetti CC, Renno ACM, Okamoto R, Cavenago BC, Duarte MH, Matsumoto MA (2016) Experimental maxillary sinus augmentation using a highly bioactive glass ceramic. J Mater Sci Mater Med 27:41. https://doi.org/10.1007/s10856$015-5652-7$
31. Osorio C, Cavalla F, Paula-Lima A, Diaz-Araya G, Vernal R, Ahumada P, Gamonal J, Herandez M (2015) H2O2 activates matrix metalloproteinases through the nuclear factor kappa $\mathrm{B}$ pathway and $\mathrm{Ca} 2+$ signals in human periodontal fibroblasts. J Periodontal Res 50(6):798-806. https://doi.org/10.1111/jre.12267

32. Cavalla F, Osorio C, Paredes R, Valenzuela MA, García-Sesnich J, Sorsa T, Tervahartiala T, Hernández M (2015) Matrix metalloproteinases regulate extracellular levels of SDF-1/CXCL12, IL-6 and VEGF in hydrogen peroxide-stimulated human periodontal ligament fibroblasts. Cytokine 73(1):114-121. https://doi.org/10. 1016/j.cyto.2015.02.001

33. Maiorana C, Beretta M, Salina S, Santoro F (2005) Reduction of autogenous bone graft resorption by means of Bio-Oss coverage: a prospective study. Int J Periodontics Restorative Dent 25(1):19-25. https://doi.org/10.11607/prd.00.0620

34. Martins CH, Carvalho TC, Souza MG, Ravagnani C, Peitl O, Zanotto ED, Panzeri H, Casemiro LA (2011) Assessment of antimicrobial effect of Biosilicate against anaerobic, microaerophilic and facultative anaerobic microorganisms. J Mater Sci Mater Med 22(6):1439-1446. https://doi.org/10.1007/s10856-011-4330-7

35. Marx RE (2007) Bone and bone graft healing. Oral Maxillofac Surg Clin North Am 19(4):455-466. https://doi.org/10.1016/j.coms. 2007.07.008

36. Sugita S, Matsumoto T (2013) Quantitative measurement of the distribution and alignment of collagen fibers in unfixed aortic tissues. J Biomech 46(7):1403-1407. https://doi.org/10.1016/j. jbiomech.2013.02.003

37. Vieira AE, Repeke CE, Ferreira Junior SB, Colavite PM, Biguetti CC, Oliveira RC, Asssis GF, Taga R, Trombone APF, Garlet GP (2015) Intramembranous bone healing process subsequent to tooth extraction in mice: micro-computed tomography, histomorphometric and molecular characterization. PLoS One 10(5): e012802 doi:https://doi.org/10.1371/journal.pone.0128021, e0128021

38. Lu M, Rabie AB (2006) Matrix metalloproteinase-9 regulates graft bone resorption. Angle Orthod 76(4):598-604 